\title{
GEOPOLÍTICA DE LOS AEROPUERTOS DEL SUR DEL PERÚ: AEROPUERTO DE CHINCHERO ${ }^{1}$
}

Julián Palacin Fernández²

\section{RESUMEN}

El presente articulo aborda el tema de la geopolítica aeroportuaria. Su objetivo es la búsqueda de los datos geográficos de la región Macro Sur Oeste y Este del Perú y establecer la priorización de políticas de cielos abiertos en terceras y cuartas libertades de la mencionada región. El autor también desarrolla un proyecto de acuerdo transfronterizo multilateral de utilización de aeropuertos fronterizos con aeronaves en la búsqueda del mercado low cost. Y finaliza comentando el nuevo terminal aéreo Chincheros su concesión y ventajas del proyecto.

\section{ABASTRACT}

This article addresses the topic of airport geopolitics. Its objetive is the search of the geographic data of the region Macro South West and East of Peru and to establish the prioritization of policies of open skies in third and fourth freedoms of the mentioned region. The author also develops a draft multilateral cross-border agreement for the use of borde airports with aircraft in search the low-cost market. And ends by commenting on the new Chincheros air terminal, its concession and project advantages.

\section{PALABRAS CLAVES}

Geopolítica. Infraestructura Aeroportuaria. Hub. Low Cost. Acuerdos trasfronterizos. Trasporte aéreo. Concesión.

\section{KEYWORDS}

Geopolitics. Airport Infraestructure. Cross-border agreements. Air transport. Concession.

La Geopolítica es una ciencia intermedia entre la Política y la causalidad espacial de los factores geográficos y el entorno físico que se ejerce sobre la organización y comportamiento regional que en el ámbito nacional los Estados estructuran en sus relaciones de poder en el contexto internacional de las naciones.

\section{INICIOS Y EVOLUCIÓN HISTÓRICA}

"La geopolítica es una disciplina que fundó el geógrafo de origen sueco Rudolf Kjellén.
En 1900 con su libro "Introducción a la geografía sueca" expuso los rudimentos básicos de la misma. En 1916 produjo su libro más importante: "El Estado como organismo viviente" (Staten som livsform), donde el término geopolítica fue utilizado por primera vez.

1 Conferencia Magistral dictada por Julián Palacín Fernández en el Salón Porras Barrenechea del Congreso de la República del Perú el viernes 2 de setiembre del 2016, organizada por el Congresista por Tacna Guillermo Martorell Sobero, Miembro de la Comisión de Transportes.

2 Ex Presidente de CORPAC, Presidente de la Comisión de Derecho Aeronáutico del CAL, Abogado del Estudio Jurídico Julián Palacín Abogados, Presidente del Instituto Peruano de Derecho Aéreo (IPDA) 
Los principios de dicha ciencia en el pensamiento geoestratégico habían sido tratados por el también geógrafo alemán Friedrich Ratzel. Según éste, los Estados tienen muchas de las características de los organismos vivientes. También introdujo la idea de que un estado tenía que crecer, extender o morirse dentro de "fronteras vivientes", por ello tales fronteras son dinámicas y sujetas al cambio". ${ }^{3}$

En consecuencia, podemos afirmar que la Geopolítica aeroportuaria es la posición que debe tener el Estado en "el desarrollo del conjunto de instalaciones y servicios ubicados en la superficie terrestre que hacen posible la navegación aérea en razonables condiciones de seguridad, regularidad y eficiencia que comprenden: a) Aeródromos y campos o espejos de agua conveniente para el desarrollo de las actividades aéreas; b) Instalaciones y equipos de abastecimiento; c) Pistas, hangares y talleres; d) Instalaciones y equipos de iluminación, señalización y balizamiento; e) Instalaciones y equipos mecánicos, sanitarios y eléctricos, f) Instalaciones y equipos de radiocomunicación aeronáuti$\mathrm{ca}, \mathrm{g})$ Instalaciones y equipos meteorológicos, h) Estaciones terminales y otras comunicaciones para pasajeros, i) Zonas urbanizadas destinadas a la aviación militar y civil, incluso edificios $e$ instalaciones". ${ }^{4}$

El objetivo de esta investigación es la búsqueda de los datos geográficos de la Región Macro Sur Oeste del Perú (Ica, Arequipa, Moquegua y Tacna) y de la Región Macro Sur Este (Cuzco, Puno, Ayacucho, Madre de Dios y Apurímac) al servicio de un desarrollo de los aeropuertos que permita en los próximos 50 años la captación de 20 millones de turistas anuales que recibirá la región sur del Perú a través de los hubs aeroportuarios ${ }^{5}$ que proponemos en esta nueva geopolítica aeroportuaria y que llegarán directamente de los centros internacionales emisores de turismo receptivo, además del beneficio de la disposición de bodegas vía aérea para la exportación de los productos y mercancías regionales con fletes económicos $y$ este es el verdadero sentido que le tenemos que dar al desarrollo de la Macro Región Sur, cuyo efecto inicial al 2021-2022 cuando se termine de construir el aeropuerto de Chinchero y al final del primer año de operaciones tenemos la expectativa de la creación directa e indirecta de dos $\mathrm{mi}$ llones de puestos trabajo en la región sur del Perú. ${ }^{6}$

Estos objetivos estratégicos impulsarán la generación de una mayor oferta exportable a través del transporte aéreo de carga vía comercio exterior para lo cual se tendrá que fomentar un mayor nivel de inversión privada teniendo en cuenta las facilidades de acceso de las pequeñas y micro empresas (PYMES) peruanas a la cadena exportadora.

El desarrollo de la infraestructura aeroportuaria de la Macro Región Sur deberá tener en cuenta la participación del sector Transportes a través de la Corporación Peruana de Aeropuertos y Aviación Comercial (CORPAC) con los gobiernos regionales y locales, buscando alianzas estratégicas con el sector privado y académico de cada región.

Estas alianzas se sustentan en el hecho de que existen distintos mercados internacionales con los que se tiene que buscar una presencia creciente de la región sur del Perú en materia de turismo receptivo y comercio exterior y ese debe ser el objetivo prioritario del

3 Ver Geopolítica de Wikipedia https: //es.wikipedia.org/w/index.php?title=Geopol\%C3\%ADtica\&printable=yes.

4 Ver Libro Curso de Post Grado en Derecho Aéreo y Espacial, Tomo II, Julián Palacín Fernández, p. 633, editado por la Comisión Interamericana de Juristas Expertos en Derecho Aéreo y Espacial CIJEDAE, imprenta Piedul, Lima 1991.

5 Planteamos como estrategia desarrollar como hub internacional los aeropuertos de Tacna, Arequipa, Chinchero (Cusco), Juliaca (Puno), Puerto Maldonado (Madre de Dios).

6 Consideramos que es el sector transportes realiza las inversiones para mejorar los servicios de aeronavegación de acuerdo a los estándares internacionales, se mejoran las pistas, se construye el aeropuerto de Chinchero y se optimiza la calidad y eficiencia de los servicios aeroportuarios a cargo de los concesionarios de los aeropuertos a partir del 2021 la Macro Región Sur Este y Oeste aumentará sustancialmente el turismo receptivo y se crearían un aproximado de dos millones de puestos de trabajo.

7 A los efectos de esta investigación la Macro Región Sur Oeste incluye la infraestructura aeroportuaria de Ica, Arequipa, Moquegua y Tacna y la Macro Región Sur Este incluye Cuzco, Ayacucho, Puno, Madre de Dios y Apurímac. 
Estado en alianza o colaboración con el sector aerocomercial privado, a quienes se les permitirá el acceso a una infraestructura aeroportuaria de primer nivel. ${ }^{8}$

El sector Transportes dentro de una nueva geopolítica aeroportuaria del sur del Perú deberá tener en cuenta la priorización de aeropuertos internacionales con políticas de cielos abiertos en terceras y cuartas libertades en la región sur este y sur oeste cuando inicie negociaciones para la firma de convenios bilaterales. ${ }^{9}$

El Estado peruano como cuestión previa a cualquier geopolítica de aeropuertos deberá ratificar "la visión de CORPAC como empresa líder en América Latina en gestión aeroportuaria, caracterizada por sus altos niveles de seguridad, confiabilidad y eficiencia de los servicios de aviación civil, siendo elemento fundamental en apoyar el desarrollo e integración nacional"10 a partir de los hubs aeroportuarios que planteamos en esta estrategia y que son el aeropuerto de Chinchero en Cusco, los aero- puertos de Tacna, Arequipa, Juliaca y Puerto Maldonado que tendrán que ser tenidos en cuenta por el Ministerio de Transportes y de Relaciones Exteriores en la suscripción de convenios aéreos bilaterales que se firmen de conformidad a los Arts. $56^{\circ}$ y $57^{\circ}$ de la Constitución del Estado peruano. ${ }^{11}$

Asimismo, "la misión de CORPAC en este nuevo esquema geopolítico de aeropuertos será "prestar servicios seguros y eficientes a la aeronavegación y aeroportuarios manteniendo la infraestructura aeronáutica que asegure la plena satisfacción del usuario con adecuados niveles de competitividad y rentabilidad" 12 .

El comportamiento económico del Perú en la última década muestra un importante crecimiento en el producto bruto interno que debemos proyectar al 2066 en la Macro Región Sur con la finalidad de desarrollar la infraestructura aeroportuaria que necesitamos para acercar los mercados internacionales de turismo receptivo y comercio exterior.

La tendencia creciente del tráfico aéreo internacional de pasajeros y carga, la modernización de las aeronaves de última tecnología con el aumento de la capacidad de asientos y de carga, además de las fusiones y/o alianzas estratégicas de las mega transportadoras a nivel regional nos deben llevar a una visión aeropolítica global con la finalidad de potenciar las posibilidades de turismo y comercio exterior de la región sur del Perú y para ello, se tendrá que plasmar el objetivo del incremento de las operaciones aeroportuarias a través de líneas aéreas nacionales y extranjeras en la búsqueda de más negocios internacionales y de un aumento significativo del turismo receptivo de la región sur del Perú.

La tendencia mundial de creación de nuevos espacios económicos en América viene consolidando los bloques económicos y para ello la Geopolítica de desarrollo del sur del Perú tendrá que tener presencia del Ministerio de Relaciones Exteriores en una participación activa en los bloques regionales incluyéndose en cualquier negociación aérea bilateral, el otor-

8 Ver Conferencia “La Política exterior peruana en los nuevos desafíos de UNASUR, las relaciones aéreas internacionales”. Julián Palacín Fernández. Seminario internacional, 12/12/12, Ministerio de RR.EE., publicado en el libro Colegio de Abogados de Lima, Comisión Consultiva de Derecho Aeronáutico del Espacio y de la Aviación Comercial, p.p.12-55.

9 Se tendrá que diseñar a mediano plazo la priorización de aeropuertos internacion"!ales que podrían ser Tacna, Chinchero en Cuzco, Juliaca en Puno, y Madre de Dios y Arequipa con una política de promoción para el acceso del low cost internacional.

10 Ver Informe de la Sub Comisión de Transferencia de CORPAC Tomo I, Julián Palacín Fernández, Visión de CORPAC p. 4, 2001.

11 Ver carta EJP-620-2016 del Estudio Jurídico Julián Palacín Abogados del 22/08/16 al Sr. Viceministro de Relaciones Exteriores del Perú Néstor Popolizio Bardales en 88 pags. Ingresada al Ministerio de RREE el 22/08/16 a las $12: 26 \mathrm{hrs}$ en donde se da un alcance legal a los Arts. $56^{\circ}$ y $57^{\circ}$ de la Constitución en relación a las Actas o Memorandas de Entendimiento firmadas por la DGAC con Chile ratificadas por el Ministro de Transportes vía RM sin el cumplimientos de los referidos artículos de la Constitución.

12 Ver Informe de la Sub Comisión de Transferencia de CORPAC Tomo I, Julián Palacín Fernández, Visión de CORPAC p. 4, 2001. 
gamiento de rutas de y hacia los aeropuertos internacionales de la Región Macro Sur del Perú. ${ }^{13}$

Consideramos que en las próximas cinco décadas se tiene que implementar una nueva estrategia geopolítica aeroportuaria en donde el aeropuerto de Chinchero ${ }^{14}$ en Cusco, el aeropuerto de Tacna ${ }^{15}$, aeropuerto de Arequipa $^{16}$, el aeropuerto de Juliaca y el aeropuerto de Puerto Maldonado, estos cinco aeropuertos internacionales deberían ser hub regionales e internacionales ${ }^{17}$ deberíamos mejorar la infraestructura del aeródromo de $\mathrm{Ilo}^{18}$, Nazca ${ }^{19}$, Andahuaylas ${ }^{20}$ y Moquegua. ${ }^{21}$
Los nuevos hubs aeroportuarios que planteamos merecerán una acción conjunta que nos permita aumentar la resistencia de las pistas para recibir aeronaves de mayor envergadura y en algunos casos superar las limitaciones en las dimensiones de las pistas, tanto como en amplitud como en longitud, teniendo en cuenta que en la mayoría de terminales aéreos además fueron diseñados para una tecnología de los años sesenta y que ahora ya privatizados tendrán que modernizarse.

CORPAC como empresa del Estado tendrá que estudiar el equipamiento en comunica- ciones, radio ayudas, y sistemas de iluminación, y además, es la entidad que tiene el personal técnico idóneo con nivel $\mathrm{OACl}$, para darle al Estado el asesoramiento que requiere en esta nueva geopolítica de desarrollo de los aeropuertos del sur.

En los últimos años, hemos asistido a restricciones y desfases en la aprobación por parte del Ministerio de Economía y Finanzas (MEF) del presupuesto de CORPAC, sin tener en cuenta que esta empresa del Estado es la propietaria del Aeropuerto Internacional Jorge Chávez (AIJCH) y en consecuencia, además de prestar

13 Ver Discurso del Secretario General del Instituto Peruano de Derecho Aéreo, Dr. Iván Torres La Torre en el Acto académico nacional en el Convento de Santo Domingo el miércoles 6 de abril del 2016, Asociación de Graduados del Curso de Post Grado en Derecho Aéreo y Espacial (APDAE), publicado en https://www.youtube.com/ watch?v=3jLwq-74lho

14 El Aeropuerto Internacional de Chinchero es un proyecto aeroportuario, que se ubicará en Chinchero, Cuzco, Perú. La pista se localizará a 3700 msnmm a $2 \mathrm{~km}$ del pueblo de Chinchero y a $15 \mathrm{~km}$ de la ciudad de Cusco. Proyecto: Se trata de una obra en proyecto destinada a reemplazar el actual Aeropuerto Internacional Alejandro Velasco Astete, el cual se encuentra en medio de la ciudad. Este nuevo aeropuerto contempla la construcción de un nuevo terminal aéreo de nivel internacional de mayor tamaño y con proyecciones a manejar conexiones internacionales en forma directa, sin pasar por el Aeropuerto Internacional Jorge Chávez, estará ubicado en el Distrito de Chinchero a 28 km del Cusco. https://es.wikipedia.org/wiki/Aeropuerto_Internacional de Chinchero

15 Es un aeropuerto con categoría II, pista de 2,500 por $45 \mathrm{mts}$, de asfalto. El aeródromo de Nazca tiene una pista de 1000 por $18 \mathrm{mts}$ con tratamiento superior asfáltico. Ver Informe de la Sub Comisión de Transferencia de CORPAC Tomo I MTC, Julián Palacín Fernández, Situación de las Pistas; p. 24, 2001.

16 Tiene categoría II, pista de 2980 por 45 mts de asfalto. El aeródromo de Nazca tiene una pista de 1000 por 18 mts con tratamiento superior asfáltico. Ver Informe de la Sub Comisión de Transferencia de CORPAC Tomo I MTC, Julián Palacín Fernández, Situación de las Pistas; p. 25, 2001.

17 "Hub" es una palabra inglesa que significa "cubo", pieza a la que llegan y de la que parten los radios de una rueda. En el lenguaje aeroportuario define a un aeropuerto en el que una o varias compañías aéreas tienen establecido un centro de conexión o distribución de vuelos. Los hub absorben el tráfico de varios aeropuertos sirviendo como centros de conexiones a otros destinos, son por tanto un instrumento para ofrecer servicios globales. Esta organización del tráfico en estrella, en torno a un nodo geográfico, permite optimizar los enlaces aéreos desde/hacia las ciudades secundarias, que cuentan con un reducido flujo de pasajeros intercontinentales y a otros destinos de baja densidad, que no justifican la creación de vuelos directos, haciéndolos converger hacia un solo aeropuerto. Como herramienta de ordenación del territorio, los "hub" permiten a las compañías aéreas optimizar la eficacia de su red y realizar economías de escala, gracias a la concentración de los medios (optimización de la rentabilidad de los equipos y de la amortización de las inversiones). http: / / www.aceta.es/archivos/1404215659.pdf.

18 El aeródromo de llo tiene una pista de 2,500 por 45 mts. de asfalto. Ver Informe de la Sub Comisión de Transferencia de CORPAC Tomo I, MTC, Julián Palacín Fernández, Situación de las Pistas; p. 25, 2001.

19 El aeródromo de Nazca tiene una pista de 1000 por $18 \mathrm{mts}$ con tratamiento superior asfáltico. Ver Informe de la Sub Comisión de Transferencia de CORPAC Tomo I MTC, Julián Palacín Fernández, Situación de las Pistas; p. 25, 2001.

20 El aeródromo de Andahuaylas tiene una pista de 2,500 por 30 mts con asfalto. Ver Informe de la Sub Comisión de Transferencia de CORPAC Tomo I MTC, Julián Palacín Fernández, Situación de las Pistas; p. $25,2001$.

21 El aeródromo de Moquegua tiene categoría $V$ y las dimensiones de su pista son 1,600 mts. por 30 mts.; superficie de asfalto, que debería ser mejorado para abrir el tráfico comercial. Ver Informe de la Sub Comisión de Transferencia de CORPAC Tomo I MTC, Julián Palacín Fernández, Situación de las Pistas p. 25, 2001. 
los servicios de tránsito aéreo es la artífice del pago de Lima Airport Partners (LAP) al Estado peruano de USD 1,772 millones de dólares desde el inicio de la concesión el 14 de febrero del 2001 por concepto de la retribución al Estado peruano del $46.51 \%$ de los ingresos anuales. ${ }^{22}$

El concesionario del Aeropuerto Internacional Jorge Chávez $(\mathrm{AlJCH})^{23}$, Lima Airport Partners (LAP) ha informado que invirtió USD 366 millones en 15 años para mejorar la infraestructura y los servicios brindados a nuestro primer terminal aéreo, en consecuencia, es importante destacar que LAP informó públicamente que en 15 años le dio al Estado USD 1,776 millones de dólares por lo que tenemos que plantearnos qué porción alícuota de este $46.51 \%$ de estas regalías se podrán asignar para la implementación de la nueva geopolítica que planteamos para el desarrollo de los aeropuertos del sur del Perú. ${ }^{24}$

En relación a los aeropuertos y aeródromos autorizados por la Dirección General de Aeronáutica Civil (DGAC), los avances de la infraestructura aero- portuaria nos muestran que la red aeroportuaria nacional se compone de 135 instalaciones aeroportuarias autorizadas por la DGAC, compuesta por 23 aeropuertos y 75 aeródromos de los cuales 25 son administrados por CORPAC y 50 por instituciones públicas y privadas y hay 37 helipuertos administradas por instituciones públicas y privadas $^{25}$.

Se requiere del sector Transportes una política aeroportuaria que guie el accionar de la Corporación Peruana de Aeropuertos y Aviación Comercial (CORPAC) líder en América Latina en los servicios de ayudas a la navegación aérea, radio comunicaciones aeronáuticas y control de tránsito aéreo, y en relación a los concesionarios de aeropuertos, éstos deben modernizarse como negocios competitivos y rentables impulsando la diversificación de las actividades no aeronáuticas y fomentando la participación de la inversión privada en su explotación ${ }^{26}$.

Los costos para el uso de terrenos en los aeropuertos de provincias concesionados son exorbitantes y desalienta la inversión privada de las empre- sas de aviación, somos el país de los aeropuertos vacíos y no tenemos planta de combustible de aviación en estos aeropuertos, y este es un tema vital que lo abordamos dentro del período de 7 meses y medio en que me tocó presidir la Corporación Peruana de Aeropuertos y Aviación Comercial (CORPAC) entre el 19 de agosto del 2002 hasta el 30 abril del 2003, si mi gestión se hubiera prolongado, a más tardar en el 2004 hubiéramos culminado nuestro proyecto de poner plantas de combustible en los principales aeropuertos nacionales, pasaron trece años y CORPAC tuvo directorios políticos, no técnicos y la Dirección General de Aeronáutica Civil del MTC (DGAC) no tuvo brújula y se olvidó especialmente a partir del 2007 de construir, mejorar y rehabilitar aeródromos públicos, de mejorar los servicios de ayuda a la navegación, de las radio comunicaciones aeronáuticas en el control del tránsito aéreo y especialmente de incentivar el desarrollo de la aviación civil, de promover la integración nacional especialmente las zonas geográficamente aisladas, de promover la capacitación del personal aeronáutico nacional

22 Ver artículo LAP ha retribuido al Estado peruano más de USD 1,772 millones: http://aeronoticias.com. pe/noticiero/index.php?option=com_content\&view=article\&id=57697:lap-ha-retribuido-al-estado-peruano-mas-de-1772-millones\&catid=15:economia-comercio-exterior\&ltemid=580.

23 Propiedad de CORPAC y asignado al MTC.

24 CORPAC del sector transportes, es el propietario del AIJCH y este ha producido USD 1,772 millones de dólares en 15 años, es decir USD 118 millones de dólares por año, a un promedio de aproximadamente de USD 10 millones de dólares por mes y USD 300 mil dólares por día, la pregunta que yo me hago, en 15 años en qué se han invertido estos recursos y cómo podemos lograr una redistribución para alcanzar los objetivos de esta geopolítica de aeropuertos que planteamos en beneficio del sur del Perú.

25 Ver libro: Comisión Consultiva de Derecho Aeronáutico del Espacio y de la Aviación Comercial CCDACAL, Julián Palacín Fernández, Colegio de Abogados de Lima 2013, p. 49.

26 Afecta el futuro de la aeronáutica civil peruana el costo desorbitado por el uso de terrenos para empresas de aviación en los aeropuertos concesionados, un inversionista peruano quiso construir un hangar en el aeropuerto de Trujillo para dos aeronaves Beechcraft B-200 y las trabas burocráticas y los costos que le querían cobrar eran mayores a los que cobra el aeropuerto de Miami en consecuencia, tuvo que llevar sus aeronaves a la zona de la Marina en el Aeropuerto Internacional Jorge Chávez. 
mediante el apoyo a la creación y desarrollo de escuelas de aviación civil de tripulantes técnicos, aeroclubes, centro de instrucción y asociaciones aero deportivas en general. ${ }^{27}$

Creo que el Ministerio de Transportes y Comunicaciones debe trazarse objetivos estratégicos en los aeropuertos del sur seleccionados para mejorar los sistemas de navegación aérea, impulsando la investigación y el desarrollo de proyectos aeronáuticos y buscando desarrollar vía el sector privado las áreas comerciales dentro de los aeropuertos concesionados de todos aquellos negocios orientados a satisfacer la necesidad de los usuarios introduciendo directrices que garanticen cambios de calidad y gestión empresarial, no puede ser por citar un ejemplo, que se construya en el aeropuerto de Pisco, una torre de control de tránsito aéreo que tiene la visión obstaculizada por el terminal ${ }^{28}$.

Aquí hay que destacar la labor realizada por CORPAC para poder hacer posible el normal desarrollo, habiendo ejecutado una obra que permite en la actualidad a los Controladores de Tránsito Aéreo realizar sus funciones sin que se vean perjudicadas las operaciones civiles y militares en ese aeropuerto.

Otro de los temas será mejorar los sistemas de seguridad aeroportuarios, modernizando y optimizando los equipos de los diversos sistemas de seguridad a las operaciones aéreas y usuarios del aeropuerto, mejorando y remodelando la infraestructura de los terminales aéreos en función a la demanda aeroportuaria, en armonía con el medio ambiente y estableciendo las medidas de seguridad y planes de contingencia necesarias para las instalaciones aeroportuarias.

Incrementar los ingresos en los aeroportuarios no significan tasas aeroportuarias exorbitantes y antieconómicas que no respondan a los costos del servicio, es por eso que al priorizar las inversiones en la asignación de recursos se tendrá que tener en cuenta la economía de escala con metas de rentabilidad global del negocio aeroportuario, promoviendo el uso de las instalaciones aeroportuarias de la región sur del Perú como polos de desarrollo comercial, incidiendo en que las tarifas o tasas aeronáuticas y no aeronáuticas deben de estar de acuerdo a los costos para facilitar la llegada de líneas aéreas nacionales e internacionales, especialmente si aspiramos a que el Perú desarrolle un plan estratégico para captar el low cost internacional.

“El fenómeno aerocomercial de las líneas aéreas de bajo costo viene teniendo una evolución interesante a nivel internacional, Ryanair en Europa, seguirá creciendo hasta transportar 100 millones de pasajeros por año, lo que nos obliga a repensar el panorama del mercado aeropolítico de América Latina y especialmente el del Perú"29.

"Estamos convencidos que es una nueva óptica en la economía de transporte aéreo este nuevo modelo de negocio, que tiene que seguir siendo analizado especialmente la experiencia europea y su aplicación en el Perú, tratando de poner énfasis en los impactos en el sector turismo y las relaciones o problemas que puedan surgir con las líneas aéreas tradicionales que se vienen consolidando en América Latina"30.

El principio de la clave del éxito para lograr el objetivo

27 La DGAC clausuró el aeródromo de Collique, ver artículo en Aeronoticias: http: / /aeronoticias.com.pe/noticiero/index.php?option=com_content\&view=article\&id=57608:ernesto-lopez-que-clausuro-el-aerodromo-de-collique-y-favorecio-a-lan-quiere-volver-a-la-dgac\&catid=47:47\&ltemid=578.

28 Aeropuertos del Perú (ADP) al hacer su proyecto, se equivocó en el aeropuerto internacional de Pisco, lo que prueba falta de supervisión del MTC, a quién se le ocurre construir una torre de control cuya visión es tapada por el terminal aéreo y lo que tiene que investigarse es el daño y la responsabilidades pertinentes. se supone que ha tenido que consultar con la Dirección de Concesiones del MTC, pero claro, les faltó un pequeño detalle, consultar a algún Estudio Jurídico especializado en Aviación, que hubiera podido impedir el daño que hoy significa tener que operar pocas horas dicho aeropuerto con perjuicios económicos para el sector privado. Ver artículo en Aeronoticias:

Construcción del Aeropuerto de Pisco tapó la torre de control de CORPAC http://aeronoticias.com.pe/noticiero/index.php?option=com_content\&view=article\&id=55168: construccion-del-aeropuerto-de-pisco-tapo-la-torre-de-control-de-corpac\&catid=47:47\&Itemid=578.

29 Ver libro “Línea aérea de bandera de bajo costo”, Julián Palacín Fernández, p. 181, editado por Aeronoticias, Lima 2011.

30 Ver libro “Línea aérea de bandera de bajo costo”, Julián Palacín Fernández, p. 181, editado por Aeronoticias, Lima 2011. 
que el mercado aerocomercial peruano sea más abierto y de mayor competencia, sobre todo para abaratar los pasajes aéreos y ampliar las comunicaciones al interior del país es crear y mejorar la infraestructura aeroportuaria, en este caso del sur del Perú, teniendo en cuenta que los consumidores son los que demandan los billetes de pasaje de bajo precio y que prefieren en muchos casos usar la vía aérea en lugar de la terrestre.

Es por ello que consideramos interesante destacar en el modelo europeo en donde las líneas aéreas de bajo costo en un $59 \%$ de la demanda, transportan pasajeros que sin la oferta de los vuelos de bajo costo no hubieran volado ${ }^{31}$ y es a nuestro criterio este mercado internacional low cost, el objetivo número uno de la nueva geopolítica de los aeropuertos del sur del Perú que planteamos para los próximos cincuenta años, es decir, consideramos que el despegue turístico y aerocomercial del Perú debe llevar al Estado a facilitar y vigilar la libre competencia entre las empresas de transporte aéreo nacional e internacional tradicionales y las low cost internacionales que operen 0 decidan ingresar libremente al mercado peruano; combatiendo toda practica que limite ese derecho y el abuso de posicio- nes dominantes o monopólicas, ya que la política aérea debe estar orientada a impedir las prácticas de dominio o cuasi monopólicas en el espacio aéreo peruano. ${ }^{32}$

\section{LOS VUELOS \\ TRANSFRONTERIZOS COMO OBJETIVO PARA INTEGRAR EL SUR DEL PERÚ CON BRASIL, PARAGUAY, URUGUAY, BOLIVIA, CHILE Y ARGENTINA}

Proyecto de Acuerdo transfronterizo de utilización de aeropuertos fronterizos con aeronaves en la búsqueda del mercado low cost

"Proponemos que como objetivo de la política aérea regional del Perú, se promueva un acuerdo transfronterizo multilateral con Brasil, Bolivia, Uruguay, Paraguay, Argentina y Chile, de uso de infraestructura aeroportuaria con aeronaves que permitan la integración de fronteras a través de una apertura de cielos que incluya el cabotaje por empresas aéreas de estos Estados sin exigencia de reciprocidad a excepción de Chile que por su posición de dominio en nuestro mercado nacional no le puede ser aplicable este principio". ${ }^{33} 34$

"Es importante destacar que la técnica legislativa de este acuerdo multilateral debe buscar que los Estados se otorguen el derecho a embarcar pasajeros, correo y carga, tomados en el territorio cuya nacionalidad posee la aeronave (tercera libertad) y derecho de tomar pasajeros, correo y carga, destinados al territorio del Estado cuya nacionalidad posee la aeronave (cuarta libertad); además del cabotaje con la finalidad de interconectar nuestras fronteras." 35

"El transporte transfronterizo de aeronaves, desde y hacia los aeropuertos y aeródromos de frontera del Perú con Brasil, Bolivia y Chile y más allá con Paraguay, Argentina, y Uruguay, debería establecer claramente la aeropolítica a seguir en materia de integración regional dentro de un contexto de aeropuertos secundarios de frontera Low Cost, es decir con tarifas $90 \%$ más baratas por servicios aeroportuarios tradicionales $\mathrm{y}$ de navegación aérea." 36

Este es el esquema creativo que planteo y que podemos exportar a los países vecinos para diseñar una estrategia común que nos permita acercar a esos quinientos millones de pasajeros anuales que usan el low cost en sus vuelos internacionales, si solo aspiramos a un 5\% para los países señalados estamos hablando de $25 \mathrm{mi}-$

31 Ver libro “Línea aérea de bandera de bajo costo”, Julián Palacín Fernández, p. 181, editado por Aeronoticias, Lima 2011.

32 Ver libro “Línea aérea de bandera de bajo costo”, Julián Palacín Fernández, p. 64, editado por Aeronoticias, Lima 2011

33 LAN AIRLINES no necesita más derecho de cabotaje dentro del territorio peruano ya que en la práctica siendo la propietaria de LAN PERÚ, los tiene.

34 Ver libro “Línea aérea de bandera de bajo costo”, Julián Palacín Fernández, p.p. 74-76, editado por Aeronoticias, Lima 2011.

35 Ver libro “Línea aérea de bandera de bajo costo”, Julián Palacín Fernández, p.p. 74-76, editado por Aeronoticias, Lima 2011.

36 Ver libro “Línea aérea de bandera de bajo costo", Julián Palacín Fernández, p.p. 74-76, editado por Aeronoticias, Lima 2011. 
llones de pasajeros anuales, es por ello que tenemos rediseñar la política aeroportuaria, ya que no hay servicios de transporte aéreo internacional low cost sin infraestructura aeroportuaria low cost. ${ }^{37}$

"Debemos tener en cuenta que los servicios de transporte aéreo internacional deben desarrollarse bajo los principios de seguridad, regularidad y economicidad. Dentro de esta óptica, el acuerdo multilateral que incluya el cabotaje dentro de una visión creativa para la política aérea internacional, debe materializarse para lograr una efectiva y real integración fronteriza que hasta la fecha no existe." 38

\section{"La concepción aeropolíti- ca que buscan dos Estados al firmar un Acuerdo aéreo bilateral debe estar respalda-}

da por la primacía del principio de la realidad económica de la potencialidad del tráfico en mercados fronterizos que hoy dependen de la capital para los servicios de transporte aéreo internacional, lo que es un contrasentido, ya que es absurdo que un ciudadano del interior del país que desee viajar a La Paz vía aérea , tenga que viajar primero a Lima para salir del país"39 40, nuestra visión es entender que

37 El término procede de la literatura inglesa y existen tres acepciones que se relacionan en este contexto: el bajo precio o low fare, el bajo costo o low cost y el sin adornos, no frills. Las aerolíneas de este tipo ofrecen vuelos a precios más bajos que las tradicionales. Para esto, ahorran significativamente en sus costos superficiales eliminando servicios innecesarios sin afectar en nada la calidad y seguridad de las operaciones aéreas. Asimismo, debemos destacar que para que funcione este modelo de negocio aerocomercial de bajo costo en el Perú, se requiere un profundo cambio en el pensamiento gubernamental de las autoridades de aeronáutica civil de la DGAC del MTC, quienes han pasado décadas sin entender el viejo axioma del Derecho Marítimo sajón: "Ships being made to plough the seas, and not lie by the walls" (Los buques se construyeron para surcar el mar, no para arrumbar contra los murallones"). La doctrina peruana de derecho aéreo que contiene este precepto, resulta perfectamente aplicable al sistema low cost, y la podemos traducir en el siguiente principio: "Las aeronaves están hechas para surcar los cielos y no para reposar en los hangares"; esperando inspecciones técnicas o certificaciones de malos funcionarios de la DGAC que bajo el amparo de algunos ministros de transportes ineficientes, le originaron al sector privado pérdidas millonarias que hicieron que los ciudadanos fueran perdiendo el entusiasmo por invertir en la industria aérea peruana. Ahora, renovamos en este trabajo un idealismo perdido y la posibilidad de que el Perú se proyecte para las nuevas generaciones, respetando principios y normas del derecho aéreo, y permitiendo el desarrollo y crecimiento del mercado aerocomercial con una activa participación de la línea aérea de bandera de bajo costo, que a futuro, podría ser $100 \%$ privada como lo es hoy LAN Airlines en Chile. El concepto low cost surgió en los Estados Unidos, luego se extendió a Europa a principios de los 90 y de ahí al resto del mundo. Originalmente, el término era empleado dentro de la industria aérea para referirse a compañías con costos de operación bajos o menores que los de la competencia. A través de los medios de comunicación de masas, su significado varió y ahora define a cualquier aerolínea en la que se requiere poca inversión y que da servicios seguros, eficientes y económicos con las limitaciones propias de este modelo. Ver libro Ver libro "Línea aérea de bandera de bajo costo", Julián Palacín Fernández, p. 31, editado por Aeronoticias, Lima 2011.

38 Ver libro "Línea aérea de bandera de bajo costo", Julián Palacín Fernández, p.p. 74-76, editado por Aeronoticias, Lima 2011.

39 Ver libro “Línea aérea de bandera de bajo costo", Julián Palacín Fernández, p.p. 74-76, editado por Aeronoticias, Lima 2011.

40 En el Perú los tratados deben ser aprobados por el Congreso antes de su ratificación por el Presidente de la República, siempre que versen sobre el tema de soberanía (Art. $56^{\circ}$ de la Constitución) y el Presidente de la Republica puede celebrar o ratificar tratados o adherir a éstos sin el requisito de la aprobación previa del Congreso en materia que no incluyan derechos humanos, soberanía, dominio o integridad del Estado, defensa nacional, y obligaciones financieras del Estado. En este caso la Resolución Suprema que aprueba el Convenio debe ser refrendada por el Ministro de Relaciones Exteriores y por el Ministro de Transportes, sin embargo en los últimos años la DGAC ha firmado en el 2007 y 2011 Actas o Memorandas de Entendimiento con Chile entregando rutas internacionales en quintas libertades sin reciprocidad y sin pedir compensaciones, ratificadas por el Ministro de Transportes y sin el cumplimiento de los Arts. $56^{\circ}$ y $57^{\circ}$ de la Constitución, lo que originó que un Congresista de la República de la Comisión de Relaciones Exteriores interponga una denuncia penal y una demanda de acción popular Exp. № 00107-2016 ante la $3^{\circ}$ Sala Civil de la Corte Superior de Justicia de Lima, cuyo informe oral como abogado hice el 10/08/16 y el 22/08/16 puse en conocimiento del Viceministro de Relaciones Exteriores Néstor Popolizio Bardales en 88 páginas en donde le informé que como abogado externo se me encargó la defensa de los intereses del Perú en esta acción popular, que busca la inconstitucionalidad de la R.M. 412-2011MTC.02 ante la $3^{\circ}$ Sala Civil de la Corte Superior de Justicia de Lima con el petitorio de la nulidad del acuerdo con Chile en donde el Perú sin reciprocidad entregó el mercado norteamericano que es el más lucrativo del mundo a cambio de visitar pingüinos en el Polo Sur con valor cero. Ver carta EJP-620-2016 del Estudio Jurídico Julián Palacín Abogados del 22/08/16 al Sr. Viceministro de Relaciones Exteriores del Perú Néstor Popolizio Bardales en 88 pags. Ingresada al Ministerio de RREE el 22/08/16 a las 12:26 hrs. 
el tráfico aéreo internacional tiene que descentralizarse, llegar y salir del país, no puede ser sólo a través de Lima, tenemos que pensar en las regiones y en su futuro, y es por ello que el sector Transportes debe acompañar mi propuesta de mejorar la infraestructura aeroportuaria del sur del Perú e implementar esta estrategia de desarrollar cinco aeropuertos internacionales que consoliden los objetivos trazados que creo van a ayudar a eliminar definitivamente la pobreza en la Macro Región Sur.

Es por ello, que el transporte aéreo para vuelos transfronterizos entre la región sur con los países señalados, por citar un ejemplo, se tiene que llevar a cabo a través de un rediseño de la aeropolítica sub regional vigente entre los países involucrados, a fin de que las empresas de aviación, peruanas o sudamericanas, puedan explotar la potencialidad de tráfico dentro de mercados en donde existan salvaguardas para la economicidad y la rentabilidad que exige hoy atender mercados no rentables dentro de la globalización aeropolítica de liberalización vigente en el mercado del transporte aéreo internacional.

Alcanzar esta concepción de política aérea regional, dependerá precisamente de una estrategia respaldada por una normatividad, que como cuestión previa, requerirá de un plan de trabajo para alcanzar el éxito en la efectiva integración que ya se viene impulsando por citar un ejemplo entre Perú-Ecuador en relación a los vuelos transfronterizos. Podríamos comenzar pensando en plasmar a través de un nuevo Acuerdo multilateral, la regulación de los vuelos transfronterizos, desde y hacia los aeropuertos de frontera a cualquiera de los aeropuertos de Perú, Brasil, Bolivia, Argentina, Uruguay, Paraguay y Chile, es decir, tenemos que conceptualizar un Acuerdo de Política Aérea de Cielos Abiertos e inclusive comenzar a pensar imaginativamente en la llamada práctica de los Stop Over u otras innovaciones en materia de colaboración interempresaria, para hacer atractivo el negocio aerocomercial para quienes en definitiva van a arriesgar sus capitales.

La libertad básica que establece el Convenio de Chicago a los servicios no regulares, también deberá aclararse o perfeccionarse, y en todo caso, reglamentarse para facilitar la consecución de los objetivos que dicho acuerdo trató de conseguir, ya que hasta la fecha no conocemos sus resultados.

Es necesario que se analice la aeropolítica vigente para revisar las tarifas aéreas, éstas, en el caso peruano, están sujetas al Principio de Libertad. Deben revisarse también las tasas aeroportuarias aplicables a los vuelos domésticos, creando incentivos que enmienden el mal diseño y ejecución del concesionamiento de aeropuertos, ya que estos han ocasionado aumentos exorbitantes en los precios que deben pagar las empresas de aviación, aumentando claro, los costos en los servicios de navegación aérea; lo cual hace en muchos casos inviable la operación aerocomercial y por ende los objetivos de dicho acuerdo. Por eso, ne- cesitamos estudios económicos para viabilizar la política aérea regional en el ámbito latinoamericano, y de ser necesario, plasmarla en normas que nos permitan a mediano 0 largo plazo, avizorar mejores resultados.

Las autoridades de Aeronáutica Civil de los países de la región con los que hay que comenzar a conversar facilitarán, según proceda la coordinación de actividades, la difusión publicitaria y el intercambio de información para el cumplimiento de las operaciones aéreas entre los aeropuertos y aeródromos habilitados en la Región Fronteriza del sur del Perú.

El transporte de equipaje, carga y envíos postales y de mensajería, se regulara por los convenios bilaterales entre las partes o en su defecto por la normativa andina y la legislación nacional.

Las compañías aéreas comerciales podrán mantener en los aeropuertos y aeródromos habilitados de la Región Fronteriza, un depósito para las partes y repuestos de sus aeronaves, las que ingresaran libre de derechos de aduana y demás tributos, siempre que no se internen en el país y que permanezcan bajo control aduanero.

Las compañías autorizadas para el tránsito transfronterizo de aeronaves, podrán abastecerse de combustible y proveerse de lubricantes necesarios en los aeropuertos y aeródromos habilitados de la otra parte, en las mismas condiciones y con los mismos precios establecidos para las 
aeronaves nacionales en vuelos domésticos.

La infraestructura aeroportuaria existe, sin embargo debemos comenzar a pensar en aeródromos de frontera Low Cost, y a mi criterio, empezar a considerar su habilitación para vuelos internacionales, lo que requeriría una decisión sectorial del MTC, además claro, de las inversiones necesarias a cargo de las Regiones o de los concesionarios.

El mercado aerocomercial, las tasas aeroportuarias, los sobrecostos de la industria aérea, la problemática laboral aeronáutica y en general la realidad de nuestras empresas de aviación y su inserción en el mercado subregional, merecen una atención especial, habida cuenta de las nuevas perspectivas y crecimiento del mercado de transporte aéreo y turístico a nivel mundial. Dentro de esta perspectiva, debemos tratar de esquematizar las modificaciones aero políticas que requerimos.

Es necesario un acuerdo regional multilateral de transporte aéreo de los países de América del Sur que podrían estar interesados en este estrategia geopolítica que acompaña el low cost internacional, y para ello sería interesante ir agendando los primeros pasos para una conferencia internacional donde se analice el mercado y la realidad aeropolítica planteando propuestas concretas para flexibilizar el marco jurídico, y se promueva de esta forma el interés de los Estados, a través de sus líneas aéreas de bandera y empresas de aviación privada, por generar actores que potencien el reto de rediseñar nuestra geopolítica aerocomercial y turística para la integración fronteriza. Esto será posible a medida que el marco para el éxito y competitividad de estos servicios sea creado y materializado gracias a una mejor normatividad, un eficaz rol promotor del Estado y una estrategia diseñada para un plan regional de desarrollo de fronteras que modifique o reglamente el marco vigente. ${ }^{41}$

\section{EL AEROPUERTO DE CHINCHERO}

"El Aeropuerto Internacional de Chinchero es un proyecto aeroportuario, que se ubicará en Chinchero, Cuzco, Perú. La pista se localizará a 3700 msnmm a $2 \mathrm{~km}$ del pueblo de Chinchero y a $15 \mathrm{~km}$ de la ciudad de Cusco." 42

\section{Proyecto \\ "Se trata de una obra en pro- yecto destinada a reemplazar el actual Aeropuerto Inter- nacional Alejandro Velasco}

Astete, el cual se encuentra en medio de la ciudad. Este nuevo aeropuerto contempla la construcción de un nuevo terminal aéreo de nivel internacional de mayor tamaño y con proyecciones a manejar conexiones internacionales en forma directa, sin pasar por el Aeropuerto Internacional Jorge Chávez, estará ubicado en el Distrito de Chinchero a 28 km del Cusco." 43

\section{Concesión}

"La obra ya ha sido concesionada por Proinversión para su construcción siendo ganador el Consorcio Kuntur Wasi, integrado por la argentina Corporación América y el peruano Andino Investment Holding. El grupo ganador solicitó al gobierno un cofinanciamiento por US\$ 264,7 millones para el proyecto. Esto le significa al Estado un ahorro de US\$204,7 millones, pues financiará 47\% y no $78 \%$ del proyecto como estaba previsto." 44

El Aeropuerto de Chinchero permitirá que lleguen 6 millones de turistas anuales con un ingreso de 12 mil millones de dólares a la región Cusco ${ }^{45}$, lo que significará la creación de puestos de trabajo y desarrollo en la región.

Se haría realidad para el 2021 lo cual exige objetivos estratégicos y una necesidad de

41 La empresa privada en aviación es un tesoro que crea puestos de trabajo y fomenta la integración entre nuestros pueblos, sin embargo en los últimos 35 años he sido testigo de cómo algunos funcionarios públicos de la DGAC (incluyendo a ministros de transportes) por ignorancia, por desconocimiento o por sabe dios qué motivos, han tomado decisiones que han originado graves consecuencias para el sector privado que hoy debería tener mil aeronaves civiles de matrícula peruana en vuelo, en una realidad a la que ni siquiera llegamos a 100.

42 https://es.wikipedia.org/wiki/Aeropuerto_Internacional_de_Chinchero.

43 Ibíd.

44 https://es.wikipedia.org/wiki/Aeropuerto_Internacional_de_Chinchero.

45 Ver libro: Comisión Consultiva de Derecho Aeronáutico del Espacio y de la Aviación Comercial CCDACAL, Julián Palacín Fernández "Presidente de la Comisión de Derecho Aeronáutico del CAL respalda la construcción de Chinchero, Colegio de Abogados de Lima 2013. 
que CORPAC ejecute las inversiones que se van a necesitar en las ayudas a la navegación aérea, radio comunicaciones aeronáuticas y control de tránsito aéreo en el aeropuerto de Chinchero que recibirá vuelos internacionales en las aeronaves de última tecnología con una capacidad de 300 o más pasajeros en promedio. ${ }^{46}$

"El Aeropuerto Internacional de Chinchero de Cusco es un sueño que está a cinco años de hacerse realidad ${ }^{47}$. El Presidente de la República Pedro Pablo Kuczynski dijo: “...que es necesario "darle un empujón" a ese proceso "para que no se empantane" 48 ; y este es un objetivo estratégico en la nueva geopolítica de los aeropuertos del sur del Perú. El nuevo terminal aéreo será uno de los más modernos del país y América Latina. Su infraestructura será de primera y contará con tecnología de punta, porque se construirá bajo estándares internacionales" ${ }^{49}$ y tendrá categoría I.

La infraestructura aeroportuaria del Aeropuerto de Chinchero tendrá un área de operación de 40,000 metros cuadrados, casi 27 mil metros cuadrados más que el Aeropuerto Velasco Astete (AVA) de Cusco explotado por CORPAC y que se entregará a la región Cusco cuando inicie operaciones en el Aeropuerto Internacional de Chinchero.

Es importante tener en cuenta que el Aeropuerto de Chinchero con una pista de aterrizaje y despegue de 4,000 metros podrá recibir hasta 6 millones de pasajeros en un año en relación a los dos millones quinientos mil pasajeros que recibe actualmente el Aeropuerto Velasco Astete del Cusco. El AVA solo recibe 2 millones 500 mil personas.

Si el actual aeropuerto Velasco Astete de Cusco solo puede recibir los aviones Airbus 321 y Boeing 737-800 que tienen una capacidad para transportar hasta 190 pasajeros como máximo, Chinchero estará capacitado para el aterrizaje de naves Airbus 340 y Boeing 787 de 300 personas en promedio.

Otra ventaja de Chinchero es que funcionará todo el día. El Velasco Astete opera entre las 5.00 de la mañana y 8.00 de la noche.
Una vez concluida la obra aeroportuaria, la concesionaria del aeropuerto de Chinchero, Kuntur Wasi operará el terminal aéreo durante 35 años. Se calcula que en ese periodo la región Cusco obtendrá una ganancia neta de 70 mil millones de dólares por la captación de pasajeros, en un promedio de 6 millones de turistas anuales. Habrá una evolución desde 4 mil hasta 6 mil millones de dólares de beneficio por año y podrá recibir aeronaves Boeing 787.

Es importante destacar, que el concesionario Kuntur Wasi logró la aprobación de los estudios y permisos necesarios para la construcción del proyecto. Está a la espera de la aprobación del cierre financiero que consta de tres etapas: aprobación del fideicomiso (ya está aprobado), Endeudamiento Garantizado Permitido y de las Condiciones de Financiamiento (pendientes). Darle el visto bueno a estos pedidos está en manos de Ositran y el Ministerio de Transportes y Comunicaciones (MTC).

Si ambas entidades dan luz verde al proyecto, Kuntur Wasi tendrá el camino allanado para iniciar el movimiento

46 Sostenemos que el MTC debería asignar el $5 \%$ de las regalías del Aeropuerto Internacional Jorge Chávez por año a CORPAC, ya que esta empresa del Estado es la unidad ejecutora y la DGAC es sólo normativa, y se debería recomendar a FONAFE que no perjudique como lo viene haciendo año a año a CORPAC para que revierta sus utilidades, debería haber una política de reinversión en ayudas a la navegación aérea y los gobernantes deberían entender que CORPAC no debe ser un botín político del gobierno de turno para colocar personas que desconocen el tema aviatorio.

47 Ver artículo en Aeronoticias: Gobierno de Cusco se respaldó en Julián Palacín para construcción de aeropuerto de Chinchero http://www.aeronoticias.com.pe/ aero2008/noticiero/index.php?option=com_content\&view=article\&id=42127:gobierno-de-cusco-se-respaldo-en-julian-palacin-para-construccion-de-aeropuerto-de-chinchero\&catid=66:transporte-aereo-nacional\&ltemid=574

48 Ver Artículo en Aeronoticias: PPK considera necesario “darle un empujón" a construcción de nuevo aeropuerto del Cusco http://aeronoticias.com.pe/noticiero/index.php?option=com_content\&view=article\&i$\mathrm{d}=57702$ :ppk-considera-necesario-qdarle-un-empujonq-a-construccion-de-nuevo-aeropuerto-del-cusco-\&catid=47:47\&ltemid=578.

49 Ver Diario La República: http://larepublica.pe/impresa/sociedad/769764-aeropuerto-de-chinchero-elevara-flujo-de-visitas-6-millones. 
de tierras y la posterior edificación del aeropuerto.

"Mover todo el volumen de tierras demorará dos años. Se tendrá que remover 25 millones de metros cúbicos (m3) de tierra en Chinchero dentro del polígono de la obra. Tras ello arrancará la edificación de la infraestructura en sí misma que comprende la construcción del terminal, pistas de aterrizaje, torre de control y edificios de apoyo." 50 "La obra costará 525 millones de dólares (sin Impuesto General a las Ventas) y será cofinanciado entre el Estado peruano y Kuntur Wasi. Hasta el momento, la concesionaria ha invertido 30 millones de dólares en la obra."

\section{Ejes de Desarrollo}

"Uno de los beneficios inmediatos del proyecto será la generación de puestos de trabajo. Se calcula que en el etapa de construcción se empleará 1,500 personas y 1,000 durante la operación." 52

"Cuando Chinchero aperture sus puertas se elevará el número de visitantes a la re- gión imperial. Si ahora se recibe en promedio 2 millones 500 mil visitantes, en 2021 se captará 6 millones. Ese aumento incentivará el mejoramiento de los servicios turísticos y doblará la oferta de turistas en los centros arqueológicos." 53

"La agricultura, también tendrá su oportunidad de desarrollo. $Y$ es que el nuevo terminal aéreo contará con un amplio terminal de carga, espacio propicio para las exportaciones, abriéndole las puertas a los productos andinos al mercado internacional." 54

“El Gobierno Regional trabaja en proyectos para impulsar la exportación del maíz blanco gigante, papas nativas, quinua y café, principalmente. A ello, se sumarían los envíos de productos de artesanía." 55

"Si todo marcha bien, el nuevo aeropuerto estará en funcionamiento en el 2021." 56 Sin embargo, para lograr el objetivo estratégico en la nueva geopolítica estratégica de los aeropuertos del sur, el sector Transportes, la DGAC y COR-
PAC, deberán apoyar decididamente este proyecto.

\section{Vía hacia Chinchero}

"Mientras Kuntur Wasi construya el aeropuerto, el MTC se encargará de la construcción de una nueva vía que conecte Cusco con el aeropuerto y el Valle Sagrado de los Incas (Urubamba)."

"El MTC ya inició los estudios del expediente técnico para ejecutar la obra vial que articulará la Ciudad Imperial con el terminal aéreo." 58

"Pero no solo será la carretera. También se ampliará la actual vía Cusco - Urubamba, se habilitará un gran espacio de acceso al aeropuerto internacional y se construirán dos puentes sobre el río Urubamba. Para todas esas obras se tiene aprobado S/ 277 millones." 59

\section{REFLEXIONES GENERALES}

Una Geopolítica de los Aeropuertos del Sur del Perú, no funcionará si no entendemos las debilidades de nuestro

50 Ver Diario La República: http://larepublica.pe/impresa/sociedad/769764-aeropuerto-de-chinchero-elevara-flujo-de-visitas-6-millones.

51 Ver Diario La República: http://larepublica.pe/impresa/sociedad/769764-aeropuerto-de-chinchero-elevara-flujo-de-visitas-6-millones.

52 Ver Diario La República: http://larepublica.pe/impresa/sociedad/769764-aeropuerto-de-chinchero-elevara-flujo-de-visitas-6-millones

53 Ver Diario La República: http://larepublica.pe/impresa/sociedad/769764-aeropuerto-de-chinchero-elevara-flujo-de-visitas-6-millones.

54 Ver Diario La República: http://larepublica.pe/impresa/sociedad/769764-aeropuerto-de-chinchero-elevara-flujo-de-visitas-6-millones.

55 Ver Diario La República: http://larepublica.pe/impresa/sociedad/769764-aeropuerto-de-chinchero-elevara-flujo-de-visitas-6-millones.

56 Ver Diario La República: http://larepublica.pe/impresa/sociedad/769764-aeropuerto-de-chinchero-elevara-flujo-de-visitas-6-millones.

57 Ibíd.

58 Ibíd.

59 Ibíd. 
sistema aeroportuario, para lo cual debemos diseñar una estrategia de oportunidades entendiendo las amenazas ${ }^{60}$ tenemos que poner en debate la estrategia aeroportuaria que el Perú debe desarrollar en los siguientes años para poder afrontar temas como el exponencial incremento de las operaciones aéreas en nuestro país. Por ejemplo, no cabe duda que las operaciones aéreas esperadas en el 2015, se han duplicado y sobrepasaron las expectativas que se hicieron al realizar los análisis costo- beneficio previos a la elaboración del importante proyecto de concesionar el Aeropuerto Internacional Jorge Chavez, y por todos es conocido que al año 2021 se espera se duplique la cantidad actual del número de operaciones.

Es por esa razón que la gran obra que se espera de esa Concesión es la construcción de la segunda pista de aterrizaje del Aeropuerto Internacional Jorge Chávez (AIJCH) ${ }^{61}$ y del nuevo terminal aeroportuario, que de acuerdo a los cálculos más optimistas, y gracias a la inmediata acción tomada directamente por el actual Ministro de Transportes y Comunicaciones señor Ing. Martin Vizcarra Cornejo, estaría operando en el 2021, sin embargo, no obstante, el esfuerzo del sector Transportes es necesario buscar una solución integral y multisectorial, ya que el problema del Aeropuerto Internacional Jorge Chávez (AIJCH) ha trascendido al punto de haberse convertido en un problema de Estado que lamentablemente los sucesivos Ministros de Transportes desde el 2001 no supieron mane$j^{2} r^{62}$. No hay más que analizar, lamentablemente y por responsabilidad por omisión de los titulares del sector Transportes en los últimos años el Perú seguirá contando con una sola Pista de aterrizaje en el
Aeropuerto Internacional Jorge Chávez (AIJCH), ya que cuando entre en operación la nueva Pista, suponemos en el 2021, inmediatamente se intervendrá la segunda pista de aterrizaje, y por ser un trabajo, que según los especialistas, debe realizarse desde la remoción del mismo terreno de fundación, esta pista podría estar operando entonces a partir del 2023, año en que recién el Perú pueda contar con dos pistas de aterrizaje en su principal aeropuerto internacional. ${ }^{63}$

Debemos recordar que en junio del 2001, se me encargó la coordinación de la Sub Comisión de Transferencia de la Dirección General de Aeronáutica Civil del Perú y de la Corporación Peruana de Aeropuertos y Aviación Comercial (CORPAC) y elaboramos en 4 tomos y 6,000 páginas el diagnóstico y el Plan de los 100 días, y en el

60 Restricción y desfases en la aprobación por parte del MEF del presupuesto de CORPAC, la DGAC variando su rol normativo como ejecutor de proyectos aeroportuarios que deberían estar a cargo de CORPAC, regalías de LAP que en un $5 \%$ deberían entregarse a CORPAC, además de la falta de planificación urbana en detrimento de las ampliaciones aeroportuarias y el ineficiente desarrollo del parque aéreo nacional y deberíamos aprovechar las fortalezas del centro de capacitación para formación y desarrollo del personal especializado en aeropuertos de CORPAC, buscando claro está, oportunidades en la concesión de aeropuertos con el sector privado en proceso de transición al sistema satelital de navegación aérea, la descentralización nacional, la posición geoestratégica del país en la región y el desarrollo de los bloques económicos de la región Pacto Andino, Mercosur, Unasur, APEC e integración binacional. Ver Informe de la Sub Comisión de Transferencia de CORPAC Tomo I MTC, Julián Palacín Fernández, Visión de CORPAC p.p. 36-38, 2001.

61 La segunda pista del aeropuerto internacional Jorge Chávez debió estar construida en el 2006 según un estudio que hizo la OACI para CORPAC y en el contrato de concesión se señaló el 2012 y la adenda № 4 lo prorrogó hasta el 2015 y ahora sabemos que en el mejor de los supuestos, la segunda pista estará en el 2021.

62 Los distintos Ministros de Transportes desde el 2001, no tuvieron la visión de impulsar con la celeridad que exigía las circunstancias históricas del desarrollo del Perú a través del turismo la expropiación de los terrenos para la segunda pista, y nombraban el Directorio de CORPAC a personas sin ninguna experiencia en aviación civil, derecho aéreo, política aérea y transporte aéreo, fue lamentablemente ver cómo la ignorancia política le hizo tanto daño al futuro del Perú, nosotros iniciamos en el 2002 los grandes proyectos de radarización u otros, algunos tardaron pero se hicieron pero el punto medular fue la construcción de la segunda pista del AIJCH y los Ministros de Transportes y Directorios de CORPAC y Directores de la DGAC no se dieron cuenta, si tuvieron celeridad estos últimos para firmar lesivos acuerdos aerocomerciales con Chile violando los Arts. $56^{\circ}$ y $57^{\circ}$ de la Constitución entregando nuestra soberanía aérea en quintas libertades sin reciprocidad, para eso fueron eficientes y también lo fueron para cerrar empresas nacionales, se olvidaron del gran objetivo nacional que era la construcción de la segunda pista del AIJCH.

63 Cuando fui Presidente de CORPAC tuve una posición firme en defensa de los intereses del Estado y de CORPAC no estuve de acuerdo con la Adenda 4, que se firmó luego de mi renuncia, en razón a que ésta incluye una Cláusula, si la tecnología lo permite, LAP podría no construir la segunda pista. 
Tomo I pág. 143 punto 12.6 dije: "Se deberá reestructurar la Comisión de alto nivel para impulsar el proceso de expropiación de los terrenos adyacentes al Aeropuerto Internacional Jorge Chávez, buscando que el Estado expropie pagando la tasa más baja del arancel fijado por CONATA, para cumplir con los plazos establecidos en el contrato de concesión y con la finalidad que el concesionario Lima Airport Partners realice las obras pactadas $e$ invierta en el Perú". 64

No obstante, esta recomendación que realizáramos el 10/06/01 en el Tomo I DGAC de la Comisión de Transferencia, los sucesivos Ministros de Transportes no cumplieron con este objetivo y hoy no tenemos segunda pista en el Aeropuerto Internacional Jorge Chávez.

Es por ello, que proyectándonos más allá del 2021, sin segunda pista del AlJCH estamos ante una situación que impactaría negativamente al desarrollo del sector turismo y de comercio exterior, por lo que es urgente tomar medidas que van más allá de hacerse de áreas de las plataformas de las fuerzas armadas que han sido cedidas al Ministerio de Transportes para ser entregadas a LAP, en la anterior administración a este Gobierno de Ollanta Humala. ${ }^{65}$

Es por eso que en múltiples exposiciones el Instituto Peruano de Derecho Aéreo (IPDA) ha propuesto la necesidad de repotenciar el aeródromo de Las Palmas para ser utilizado para la Aviación General y oxigenar, el uso de los Puestos de estacionamiento y operaciones aéreas de despegue y aterrizaje en el Aeropuerto Internacional Jorge Chávez. ${ }^{66}$

Otra de las acciones es requerir a Lima Airport Partner (LAP), que proceda por Fases Constructivas a priorizar la construcción de las Calles de Rodaje al lado oeste de la actual pista de aterrizaje, con plataformas que permitan crear puestos de estacionamiento y zonas de estacionamiento interferencia ilícita, rosa de vientos y/o corrida de motores. ${ }^{67}$

Estas acciones son refrendadas por especialistas del sector aeronáutico, y existen una serie de alternativas adicionales, por lo que recomiendo que las actuales autoridades del Gobierno conformen una Comisión Especializada de Alto $\mathrm{Ni}$ vel que encuentren la solución integral este grave problema y gran reto que le ha tocado enfrentar a este Gobierno, y a quien reafirmo mi apoyo incondicional para sumar y hacer la sinergia necesaria para que nuestro Perú siga venciendo sus dificultades.

Otra forma de ayudar a oxigenar el uso de la limitante infraestructura aeroportuaria por el inminente incremento de las operaciones aéreas es repotenciar los diferentes aeropuertos que conformen los diferentes anillos turísticos, tanto en la zona norte, oriente y sur del país.

Hoy nos reúne justamente la necesidad de elaborar una Geopolítica de los Aeropuertos

64 Ver Informe de la Sub Comisión de Transferencia de DGAC Tomo I MTC, Julián Palacín Fernández, Visión de CORPAC p. 143, 2001.

65 Nosotros sostenemos que el MTC debió negociar con LAP para que las nuevas plataformas de aeronaves se construyan inmediatamente con los terrenos disponibles, el anterior Ministro nos consultó y se nos informó que LAP de acuerdo a la posición de sus accionistas no quería iniciar la construcción de la segunda pista si no se le entregaba el $100 \%$ de los terrenos, en consecuencia se estaba sacrificando las áreas de las Fuerzas Armadas habiendo terrenos ya expropiados, en fin es un tema que es competencia del sector Transportes, sin embargo, nosotros sostuvimos que se debería habilitar provisionalmente hasta el 2021 el aeródromo de Las Palmas y que en esa fecha no se le debía renovar a LAP la cláusula monopólica y que deberíamos trabajar en el gran proyecto de la construcción del Aeropuerto Internacional low cost de la Isla San Lorenzo.

66 En el 2012 le presenté un informe al Ministro de Transportes en donde la aconsejé abrir el aeródromo de Las Palmas al uso público en tanto se construya la segunda pista del AlJCH y la construcción del aeropuerto low cost de la Isla San Lorenzo.

67 Sostenemos que, Ministerio de Transportes podría negociar con el concesionario Lima Airport Partners (LAP) del Aeropuerto Internacional Jorge Chávez (AIJCH) que con el 60\% de los terrenos ya entregados se inicie la ampliación del AIJCH con parqueo para aeronaves, hangares, talleres de mantenimiento y la habilitación en general de las áreas que se requieren para la infraestructura aeroportuaria que necesita el Perú para atender el mercado especialmente los servicios de transporte aéreo regular y no regular de las líneas aéreas nacionales y de las anunciadas líneas aéreas extranjeras "low cost" que desean llegar al Perú a partir del 2017.Esta decisión la puede tomar el MTC en consenso con LAP, en tanto se entregan las áreas de terreno pendientes para construir la segunda pista del AIJCH en donde el concesionario LAP en cumplimiento del contrato de concesión deberá invertir mil doscientos millones de dólares. 
del Sur del Perú, y existe muchas formas de repotenciar los aeropuertos del Sur que en la actualidad han sido concesionados, es decir, Ayacucho, Juliaca, Arequipa, Pisco, Tacna y Puerto Maldonado, pero para ello mis estimados invitados de honor, solicito con todo respeto a nuestro excelentísimo Ministro de Transportes señor Martín Vizcarra se procede a disponer a la Dirección General de Aeronáutica Civil, elabore y publique el Plan Nacional de Navegación Aérea el mismo que debe estar enmarcado en la Metodología de Mejoras por Bloques del Sistema de Aviación (ASBU) que la $\mathrm{OACl}$ ha puesto en consideración con todos los estados Contratantes con la finalidad de lograr un desarrollo integral de la Aviación Civil en el Mundo. De la misma manera me permito sugerir se proceda a disponer a la misma DGAC que elabore un Plan Nacional de Desarrollo de Infraestructura Aeroportuario que permita crecer en forma sistemática en infraestructura aeroportuaria, fortaleciendo la descentralización de la propia administración de los aeropuertos a los gobiernos regionales y locales del país, pero de una forma que permita la sostenibilidad del servicio del transporte aéreo. Aquí un pequeño ejemplo, el aeródromo de ILO, es un aeródromo que ha sido preparado para poder servir como el enlace entre Bolivia y el Perú, de tal forma que se desarrolle el enlace multimodal del transporte aéreo y marítimo, fortaleciendo nuestra relación con nuestros hermanos bolivianos, y por supuesto, desarrollando al pueblo siempre pujante de Ilo. Hace unos años operó un operador de Transporte Aéreo,
Peruvian Airlines, sin embargo, no hubo una continuidad, y no la hubo ya que se trata de que el Estado debe procurar un marco de interés como el turístico y otros que permita la debida sostenibilidad, estamos seguros que con el ingreso de nuevas aeronaves de menor capacidad y que responden positivamente a realizar vuelos comerciales regionales, como las recientemente adquiridas por LC Perú y Star Perú, siendo esta última empresa la que ya ha mostrado interés en forma oficial de volar a ILO, por lo que es posible que nuevamente el retorno de operaciones en ese aeródromo que en la actualidad es administrado por CORPAC.

Otro aspecto que debe contemplar ese Plan Nacional de Desarrollo de Infraestructura Aeroportuaria es fortalecer el sistema de formación de Pilotos, por el gran déficit existente de los mismos, para ello, se debe realizar la investigación necesaria y de los resultados de ella se tomen las acciones pertinentes que permitan reactivar el proceso de construcción del aeródromo de Grocio Prado en Chincha, cuya obra ha quedado paralizada desde hace más de dos años, habiéndose construido ya la pista de aterrizaje. No olvidar que de la misma manera se puede repotenciar y adecuar aeródromos como el de Chimbote para que el Estado pueda con el apoyo de los actuales explotadores de transporte aéreo elaborar un Proyecto que permita contar en el corto y mediano plazo con nuevas promociones de pilotos peruanos que puedan atender la gran demanda existente, que de la misma manera seguirá creciendo.
Por otro lado, es necesario, así como el norte y el nor oriente, desarrollar un anillo turístico que se enlace vía aérea, y que cubra la zona sur, un Anillo turístico que podría estar integrado por Nasca, Ayacucho, Arequipa, Cusco y Puerto Maldonado (Manu). Es por esa razón que el Plan de Nacional de Desarrollo de la Infraestructura Aeroportuaria debe responder a estos grandes retos e incluya en su visión las necesidades más importantes de desarrollo que tiene nuestro país en infraestructura aeroportuaria, y podamos contar con un Aeropuerto que pueda cumplir con los requerimientos de seguridad que por ejemplo, el actual Aeródromo de Nasca no cumple y que por ello se encuentra limitado para poder crecer en infraestructura para soportar mayor número de operaciones. Por ello se hace necesario ir evaluando la posibilidad de construir un nuevo aeropuerto.

En el caso de Cusco, CORPAC debería a estas alturas tener la claridad del horizonte de tiempo en que las operaciones aún se realizarán en el Aeropuerto Velazco Astete, de tal forma que pueda responder con un proyecto que permita soportar el constante incremento de operaciones que tendrá en los siguientes 6 años o más, tiempo que estimo estará concluido el Aeropuerto Internacional de Chinchero. No hay que olvidar la reciente incorporación de vuelos Internacionales directos desde Bogotá al Cusco y el interés mostrado por operadores de transporte aéreo internacionales pertenecientes a los países integrantes de la Cooperación Económica Asia Pacífico (APEC). 
Puerto Maldonado cuenta con una Infraestructura Aeroportuaria que no está debidamente explotada, y así podríamos hablar operacionalmente de la infraestructura aeroportuaria que requiere de una intervención urgente, y el aceleramiento de las inversiones por parte de los concesionarios, y en el caso de Cusco, por CORPAC. Sin embargo, no se puede dejar de mencionar los grandes esfuerzos de inversión que ha realizado la Corporación Peruana de Aeropuertos y Aviación Civil en estos últimos años, donde ha superado más de los 80 Millones de dólares en la adquisición, instalación y puesta en marcha una plataforma de soporte tecnológico para la aeronavegación, de última generación preparándose para enfrentar los grandes retos de crecimiento de las operaciones aéreas, y lo más importante garantizando la seguridad de las operaciones aéreas con su capital más importante, el humano representado por el personal operacional y técnico especializado que día a día entregan su vida haciendo de la navegación aérea en nuestro país uno de los más seguros en América Latina, respondiendo a su lema: "Cielos peruanos en buenas manos".

Todo esta inmensa labor de desarrollar la Infraestructura aeroportuaria en nuestro país, sólo podrá ejecutarse siempre y cuando se revisen Decretos Supremos como el D.S. N ${ }^{\circ} 019$ 2007. MTC, por medio del cual se establecen los criterios de clasificación de la infraestructura aeroportuaria del país y la jerarquización de aeródromos de propiedad pública, con la finalidad de ser trans- feridos a los Gobiernos Regionales y Locales. Es claro que tales Instituciones del estado no están preparadas a soportar los requerimientos legales, técnicos y operacionales, especializados en materia de aviación civil, exigidos por la Organización de Aviación Civil Internacional $(\mathrm{OACl})$, por lo que normas como estas deben ser reevaluadas para que no se conviertan en letra muerta tal como hasta la fecha se ha convertido.

A pesar de la inversión ejecutada y programada por CORPAC, resulta evidente que no es suficiente el Perú crece en forma exponencial y de la misma manera debe reflejarse el nivel de inversiones que debe realizarse en el sector aeronáutico y aeroportuario. Por ello es necesario cambiar ciertas costumbres, por ejemplo, ¿qué han hecho los Gobiernos anteriores con las utilidades de CORPAC?, hasta el momento en lugar que esas utilidades sean revertidas en inversiones y mejora de la calidad de vida del importante capital humano con el que cuenta esa empresa, FONAFE exige todos los años que se revierta hacia sus accionistas, tal como nuevamente se realizó en el presente año donde CORPAC depósito más de 60 millones de soles a FONAFE, en lugar de atender el pedido de mantener ese dinero para hacer la Caja necesaria para realizar ejecutar las grandes inversiones programadas para el futuro como son equipamiento total con nuevos sistemas de ayudas para la aeronavegación en los aeropuertos de Chinchero y para la segunda Pista del Aeropuerto Internacional Jorge Chávez, entre otros grandes proyectos que persigue CORPAC como el ya informado en los medios de comunicación respecto a la Construcción de un nuevo Centro de Control de Tránsito Aéreo, cuyo objetivo es mantener la continuidad del servicio de navegación aérea en el país, en el caso exista un desastre natural que no permita la operatividad del existente en Lima. Estamos seguros que este Gobierno cambiará las cosas, y dé nuevos lineamientos que propicien inversiones también este importante y sensible mundo de la aviación civil.

Finalmente, es importante señalar que el Perú no debe quedarse sin tener la presencia necesaria en Foros Internacionales de Aviación Civil tales como la $\mathrm{OACl}$, donde países vecinos y hermanos nos están llevando la delantera teniendo presencia en los Consejos de Seguridad de la Aviación Civil, y otro Consejos, haciendo posible que sus representantes puedan apuntalar posiciones que nos llevarían inclusive a perder la posibilidad que el Perú pierda su condición de ser Hub en América del Sur en materia de Transporte Aéreo.

\section{CONCLUSIONES FINALES}

1. El sector Transportes deberá encargar a CORPAC para que en el plazo de 90 días prepare un estudio para la modernización de los servicios de ayuda a la navegación aérea y radio comunicaciones aeronáuticas en los aeropuertos de Pisco, Nazca, Arequipa, Moquegua, Ilo y Tacna; y Cusco, Puno, Juliaca, Ayacucho y Puerto Maldonado. 
2. Se tendrá que hacer una evaluación de dichos terminales a cargo de los concesionarios y del Aeropuerto Velasco Astete de Cusco explotado por CORPAC con las propuestas de inversiones para mejorar la infraestructura y el MTC destinará el $5 \%$ de las regalías de LAP a la nueva geopolítica de los aeropuertos del sur del Perú entre el 2016 al 2021.

3. El Ministro de Transportes tendrá que nombrar un Comité Consultivo de $\mathrm{Ae}$ ronáutica Civil cumpliendo el Art. $13^{\circ}$ de la Ley 27261 que emitirá opinión y formulará recomendaciones y que deberá sesionar una vez al mes con el Director de la DGAC y el Presidente de CORPAC, debiendo informar al Ministro de Transportes cada tres meses los avances de la nueva geopolítica de desarrollo de los aeropuertos del sur del Perú.

4. El sector Transportes en la firma de los convenios bilaterales con los distintos países del mundo de conformidad a los Arts. $56^{\circ}$ y $57^{\circ}$ de la Constitución Política del Perú negociará y otorgará con política de cielos abiertos en terceras y cuartas libertades los aeropuertos internacionales designados en la geopolítica aeroportuaria del sur del Perú. 68

5. El sector Transportes deberá garantizar la existencia de plantas de almacenamiento de combustible de aviación en los aeropuertos del Perú. ${ }^{69}$

6. La Dirección General de Aeronáutica Civil deberá cumplir su rol previsto en el Art. $4^{\circ}$ de la Ley 27261 de:

6.1. Apoyar la creación y desarrollo de las escuelas de aviación civil y aeroclubes. ${ }^{70}$

6.2. Fomentar la creación y desarrollo de los aeródromos públicos y privados, otorgando las facilidades que sean convenientes para este propósito. ${ }^{71}$

6.3. Publicar el plan de navegación aérea. ${ }^{72}$

6.4. Elaboración del Plan Nacional de Desarrollo de Infraestructura Aeroportuaria.

7. El sector Transportes en la firma de convenios bilaterales deberá respetar los Arts. $56^{\circ}$ y $57^{\circ}$ de la Constitución, los Ministros de Transportes no deben permitir que los Directores de Aeronáutica Civil (DGAC) con los intereses de las mega empresas in- ternacionales que dominan el mercado firmen Actas de Entendimiento a puertas cerradas sin debate público y sin que participen como observadores la sociedad civil representada por la Comisión de Derecho Aeronáutico del Colegio de Abogados de Lima y el Instituto Peruano de Derecho Aéreo, además de CORPAC.

8. Planteamos que el sector Transportes con el 1\% de las regalías que paga LAP al año en convenio con la escuelas de aviación civil de prestigio y debidamente certificadas y en convenio con las regiones, cree una escuela de aviación civil y un aeroclub en cada región del Perú, comenzando por la Macro Región Sur y otorgando 20 becas integrales anuales para seguir el curso de pilotaje a los mejores alumnos de las escuelas nacionales que quieran seguir esta profesión.

9. Los aeropuertos internacionales de Tacna, Arequipa, Juliaca, Chinchero (Cusco) y Puerto Maldonado a través de un comisionado de alto nivel internacional en derecho aéreo, negociará con las líneas aéreas internacionales y con las low cost del mundo las condiciones y facilidades en los aeropuertos mencionados

68 El Perú en intercambio de los derechos de trafico deberá negociar con otros países como punto de entrada y salida los aeropuertos internacionales de Arequipa y Tacna, Juliaca, el aeropuerto Velasco Astete, hasta que inicie operaciones el aeropuerto de Chinchero y el aeropuerto de Puerto Maldonado.

69 Durante mi gestión en la presidencia de CORPAC 2002-2003 este proyecto estaba sumamente avanzado, inclusive fui invitado por Aeropuertos y Servicios Auxiliares (ASA) de México, 13 años después ningún directorio de CORPAC siguió este proyecto y los Ministros de Transportes no se dieron cuenta que sin combustible de aviación en los aeropuertos no hay posibilidad de desarrollo.

70 Ver Art. $4^{\circ}$ inciso e) de la Ley 27261 Ley de Aeronáutica Civil del Perú.

71 Ver Art. $4^{\circ}$ inciso h) de la Ley 27261 Ley de Aeronáutica Civil del Perú.

72 Ver Art. $4^{\circ}$ inciso j) de la Ley 27261 Ley de Aeronáutica Civil del Perú. 
que le otorgará el gobierno peruano para que lleguen al Perú con los beneficios en las tasas de navegación aérea y uso de aeropuertos que establecerá la normativa que se ponga en vigencia para cumplir estos fines en beneficio del desarrollo de la Región Sur del Perú.

10. Se debe modificar el Decreto Supremo $\mathrm{N}^{\circ}$ 0192007-MTC por el cual se establecen los criterios de clasificación de la infraestructura aeroportuaria del país y la jerarquización de los aeródromos de propiedad pública, con la finalidad de ser transferidos a los gobiernos regionales y locales, soy de la opinión que los gobiernos regionales y locales no están preparados para explotar aeropuertos, no podrían cumplir con los requerimientos legales, técnicos y operacionales exigidos por el Convenio Sobre Aviación Civil Internacional y los Anexos $\mathrm{OACl}$ y los instrumentos internacionales suscritos y ratificados por el Perú y la Ley 27261 y su Reglamento y los Requeri- mientos de la Organización de Aviación Civil Internacional $(\mathrm{OACl})$, la única entidad preparada académicamente y técnicamente para realizar esta tarea en el Perú es la Corporación Peruana de Aeropuertos y Aviación Comercial (CORPAC), no se puede poner en riesgo la seguridad de la aviación civil y la vida de millones de pasajeros y tripulantes entregando la explotación de aeropuertos nacionales o internacionales a los gobiernos regionales y locales; éstos podrían administrar pistas de aterrizaje.

11. El sector Transportes deberá solicitar que FONAFE apruebe que CORPAC reinvierta hasta el 2021 sus utilidades en las inversiones que requieran esta geopolítica de desarrollo de los aeropuertos del sur del Perú.

12. Se deberá revisar la Certificación y Operación de aeropuertos que sirven a los transportadores aéreos RAP 139 incluido el concesionario del Aeropuerto
Internacional Jorge Chávez y fiscalizar que las obligaciones de LAP, con los fondos del pago del TUA le den las facilidades de infraestructura y buenas instalaciones y servicios a la Aduana-SUNAT, Policía de Migraciones, DIRANDRO y que se restituya la Sala de Prensa del Aeropuerto Internacional Jorge Chávez.

13. Se debe aprobar el Proyecto de Ley del Régimen de admisión temporal de aeronaves de matrícula peruana y de operadores nacionales que permite el ingreso de mercancías extranjeras con suspensión del pago de derechos arancelarios y demás impuestos que gravan su importación, además se debe considerar una depreciación del $20 \%$ al año y la posibilidad de nacionalización al quinto año, de manera que cuando se nacionaliza el valor contable será cero y no pagará nada por concepto de IGV que será aplicado solo a las aeronaves de matrícula peruana importadas por empresas de aviación peruanas. $^{73}$

Facebook: Julián Palacín Fernández Facebook: Instituto Peruano de Derecho Aéreo Facebook: Comisión Interamericana de Juristas Expertos en Derecho Aéreo y Espacial Facebook: Historia del Derecho Aéreo Peruano www.estudiojuridicopalacin.com jpalacin@estudiojuridicopalacin.com ejp@terra.com.pe

73 La industria aérea peruana pasa por su peor crisis de la historia ilegal e inconstitucionalmente se cerró el Aeródromo de Collique. No se ha aprobado en el Congreso la Ley de Admisión Temporal, se negocian vía Actas de Entendimiento aprobadas por Resolución Ministerial derechos de tráfico del Perú al mercado norteamericano sin reciprocidad y sin pedir compensaciones. La DGAC no ha venido respetando los Arts. $56^{\circ}$ y $57^{\circ}$ en los convenios con Chile, a Lan en una clara competencia desleal en perjuicio de sus competidores se les estaría permitiendo la adquisición de combustible de aviación sin pagar IGV y la utilización de aeronaves de matrícula extranjera permite que se evadan los RAPs, lo que exige que alguien ponga orden en el espacio aéreo peruano y en materia aeroportuaria la tendencia en los últimos 13 años fue nombrar directorios políticos y no técnicos en CORPAC lo cual debe revaluarse por el bien del país. 